\title{
Bioavailability of ibuprofen following oral administration of standard ibuprofen, sodium ibuprofen or ibuprofen acid incorporating poloxamer in healthy volunteers Peter M Dewland ${ }^{1}$, Sandie Reader ${ }^{2}$ and Phillip Berry*2
}

Address: ${ }^{1}$ Simbec Research, Merthyr Tydfil, CF48 4DR, UK and 2Reckitt Benckiser Healthcare UK, Dansom Lane, Hull, HU8 7DS, UK

Email: Peter M Dewland - peter.dewland@btinternet.com; Sandie Reader - sandie.reader@ntlworld.com;

Phillip Berry* - phillip.berry@reckittbenckiser.com

* Corresponding author

Published: 4 December 2009

BMC Clinical Pharmacology 2009, 9:19 doi:10.1 186/1472-6904-9-19
Received: 4 March 2009

Accepted: 4 December 2009

This article is available from: http://www.biomedcentral.com/1472-6904/9/19

(c) 2009 Dewland et al; licensee BioMed Central Ltd.

This is an Open Access article distributed under the terms of the Creative Commons Attribution License (http://creativecommons.org/licenses/by/2.0), which permits unrestricted use, distribution, and reproduction in any medium, provided the original work is properly cited.

\begin{abstract}
Background: The aim of this study was to compare the pharmacokinetic properties of sodium ibuprofen and ibuprofen acid incorporating poloxamer with standard ibuprofen acid tablets.

Methods: Twenty-two healthy volunteers were enrolled into this randomised, single-dose, 3-way crossover, open-label, single-centre, pharmacokinetic study. After 14 hours' fasting, participants received a single dose of $2 \times 200 \mathrm{mg}$ ibuprofen acid tablets (standard ibuprofen), $2 \times 256 \mathrm{mg}$ ibuprofen sodium dihydrate tablets (sodium ibuprofen; each equivalent to $200 \mathrm{mg}$ ibuprofen acid) and $2 \times 200 \mathrm{mg}$ ibuprofen acid incorporating $60 \mathrm{mg}$ poloxamer 407 (ibuprofen/poloxamer). A washout period of 2-7 days separated consecutive dosing days. On each of the 3 treatment days, blood samples were collected post dose for pharmacokinetic analyses and any adverse events recorded. Plasma concentration of ibuprofen was assessed using a liquid chromatographic-mass spectrometry procedure in negative ion mode. A standard statistical ANOVA model, appropriate for bioequivalence studies, was used and ratios of $90 \%$ confidence intervals $(\mathrm{Cls})$ were calculated.
\end{abstract}

Results: $T_{\max }$ for sodium ibuprofen was less than half that of standard ibuprofen (median 35 min vs $90 \mathrm{~min}$, respectively; $P=0.0002)$ and $C_{\max }$ was significantly higher $(41.47 \mu \mathrm{g} / \mathrm{mL}$ vs $31.88 \mu \mathrm{g} / \mathrm{mL}$;

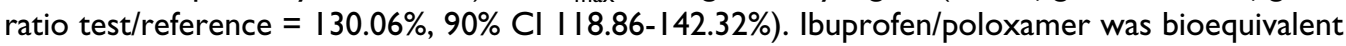
to the standard ibuprofen formulation, despite its $T_{\max }$ being on average 20 minutes shorter than standard ibuprofen (median 75 mins vs 90 mins, respectively; $P=0.1913$ ), as the ratio of test/ reference $=110.48 \%(\mathrm{Cl} 100.96-120.89 \%)$, which fell within the $80-125 \%$ limit of the CPMP and FDA guidelines for bioequivalence. The overall extent of absorption was similar for the three formulations, which were all well tolerated.

Conclusion: In terms of $T_{\max }$, ibuprofen formulated as a sodium salt was absorbed twice as quickly as from standard ibuprofen acid. The addition of poloxamer to ibuprofen acid did not significantly affect absorption.

\section{Background}

Ibuprofen $[( \pm)-(\mathrm{R}, \quad \mathrm{S})-2-4$ (4-isobutylphenyl)-propionic acid], a chiral 2-arylpropionic acid derivative non-steroi- dal anti-inflammatory drug, is a widely used and well-tolerated analgesic [1]. Although ibuprofen is a non-selective cyclooxygenase (COX) inhibitor, inhibiting both COX-1 
and COX-2 forms, its analgesic, antipyretic and antiinflammatory effects are achieved principally through COX-2 inhibition [2].

With most analgesics, including ibuprofen, the initial rise in plasma concentration following oral administration is a key factor in determining the time to onset of pain relief [3]. Ibuprofen is rapidly absorbed, and both peak plasma concentrations and maximal analgesic onset are achieved within 1.5-2 hours of oral administration [4].

Key pharmacokinetic studies have demonstrated that there is a linear dose-response relationship between the amount of drug administered and the area under the serum concentration-time curve (AUC) following single doses of ibuprofen (200-800 mg) [4]. There is also a significant correlation between plasma ibuprofen levels and the resultant degree of pain relief, particularly 1 hour after administration [5].

For orally administered standard ibuprofen formulations, it is desirable to have a formulation with a rapid rate of absorption because this is required for rapid pain relief [6]. It is well documented that ibuprofen salts, such as ibuprofen lysine and ibuprofen arginate, are more rapidly absorbed than formulations of free ibuprofen acid $[7,8]$. Another ibuprofen salt, sodium ibuprofen dihydrate (ibuprofen sodium), manufactured by Hoffmann-La Roche Ltd, was recently shown to be bioequivalent to the lysine and arginate salt forms. Several studies have shown that faster-absorbed formulations lead to faster onset of analgesia [9-14].

Reckitt Benckiser Healthcare International (Hull, UK) has also developed ibuprofen formulations that are expected to be absorbed faster than standard ibuprofen acid. The first is a sodium ibuprofen formulation containing 256 mg of ibuprofen sodium dihydrate per tablet (equivalent to $200 \mathrm{mg}$ ibuprofen acid). The second test ibuprofen formulation contains $200 \mathrm{mg}$ ibuprofen acid plus $60 \mathrm{mg}$ of the surfactant poloxamer 407 (from the poloxamer family of polymeric non-ionic surface active agents) to increase the rate of dissolution of the tablet and therefore enable more rapid absorption. Poloxamers have been used previously to enhance dissolution and bioavailability of poorly water-soluble drugs, including ibuprofen [15].

The aim of this phase I study was to compare the pharmacokinetic properties of a single dose (2 tablets) of each of the two test formulations with those of standard ibuprofen $(2 \times 200 \mathrm{mg}$ tablets) in healthy volunteers, in order to add to the growing body of evidence for the faster absorption rates of alternative ibuprofen formulations.
This study was conducted in accordance with the Declaration of Helsinki [16], as referenced in EU Directive 2001/ 20/EC3 [17] and complies with International Conference on Harmonisation, Good Clinical Practice and applicable regulatory requirements.

\section{Methods}

The study protocol, together with participant information and consent documents, were reviewed and approved by South East Wales Local Research Ethics Committee.

\section{Participants}

Healthy male and female volunteers $18-50$ years of age (mean 27.2 years) and with a body mass index (BMI) of $20-27 \mathrm{~kg} / \mathrm{m}^{2}$ (mean $24.1 \mathrm{~kg} / \mathrm{m}^{2}$ ) were included in the study. Participants had provided written informed consent.

Participants with a history of significant disease, any condition that might have interfered with the absorption, distribution, metabolism or excretion of the drugs, or a history of allergy or migraine were ineligible for the study. Those with a history of gastrointestinal disorders, cardiac disease or hypertension, or of psychotic illness were ineligible. Participants reporting frequent dyspepsia, smoking in the previous 6 months and those with a history of drug misuse (including alcohol) were excluded from the study. Participants who had ingested a prescribed drug at any time within the 14 days preceding study enrolment (excluding hormonal contraceptives and hormone replacement therapy) or an over-the-counter (OTC) preparation within 7 days preceding enrolment were also excluded, as were those who had donated blood in the 12 weeks preceding enrolment.

Further exclusion criteria included: known risk factors for AIDS or known HIV positive status, a positive viral serology screen; those with clinically significant abnormal laboratory values at screening; women of childbearing potential, who were pregnant or lactating, seeking pregnancy or failing to take adequate contraceptive precautions; those unable in the opinion of the investigator to comply fully with the study requirements; those previously randomised into the study; previous randomisation in the study or participation in a clinical trial in the previous 12 weeks; citizens of the United States of America and participants of any nationality who were not resident in the UK at the time of the study.

\section{Study design}

This study was a randomised, 3-way crossover, openlabel, single-centre, pharmacokinetic study to compare the rate of absorption (assessed from pharmacokinetic 
parameters) of one standard and two test formulations of ibuprofen given in single doses.

Participants received a single dose of $2 \times 200 \mathrm{mg}$ ibuprofen acid tablets (standard ibuprofen; Nurofen ${ }^{\oplus}$ [Reckitt Benckiser Healthcare, UK]), $2 \times 256 \mathrm{mg}$ ibuprofen sodium dihydrate tablets (sodium ibuprofen; each equivalent to $200 \mathrm{mg}$ ibuprofen acid) and $2 \times 200 \mathrm{mg}$ ibuprofen acid tablets each incorporating $60 \mathrm{mg}$ poloxamer 407 (ibuprofen/poloxamer). A washout period of 2-7 days separated consecutive dosing days.

Participants attended an initial screening visit followed by three treatment visits, each of which required the participants to stay overnight and fast for 14 hours. A post-study follow-up visit occurred 2-7 days after the final treatment visit.

Alcohol consumption was limited to two units/day in the 7 days before the screening visit and participants were required not to drink alcohol from 48 hours before admission to the end of each treatment visit (i.e. until after the 12-hour blood sample). Caffeine intake was prohibited during the study.

\section{Assessments}

A serum pregnancy test was conducted at the initial screening visit and at each treatment visit if appropriate. A urine sample was collected at each of the five visits for (1) urinalysis at the screening and post-study follow-up visits and (2) for drugs of misuse and alcohol at the pre-study visit and at each treatment visit. Haematology and biochemistry assessments were conducted at the screening visit and the post-study visit. On the three treatment days, blood samples ( $5 \mathrm{ml}$ ) were collected from all participants at 5, 10, 15, 20, 25, 30, 35, 40, 50 minutes and 1, 1.25, $1.5,1.75,2,3,6,9$ and 12 hours post dose for pharmacokinetic analyses. More frequent sampling was conducted in the first hour to obtain accurate pharmacokinetic data during the initial absorption phase.

Safety was assessed in terms of the overall number of participants with adverse events. Adverse events were recorded in the case report forms by the investigator or designee after asking participants "Have you experienced any symptoms or complaints?" before dosing, at 4 and 12 hours post dose, prior to the subject leaving the unit, and again when the subject returned to the unit for their next visit. Spontaneously reported adverse events were also recorded, and laboratory values and vital signs were monitored.

\section{Plasma ibuprofen determination}

Plasma ibuprofen determinations were performed by Simbec Research Limited using a liquid chromatographicmass spectrometry procedure (LC-MS) in negative ion mode. This procedure was fully validated over the calibration range $0.5-100 \mu \mathrm{g} / \mathrm{ml}$ and a limit of quantitation set at $0.5 \mu \mathrm{g} / \mathrm{ml}$. Volumes of $0.2 \mathrm{ml}$ of test, standard and quality control sample were spiked with $50 \mu \mathrm{g}$ flurbiprofen internal standard (i.e. $250 \mu \mathrm{g} / \mathrm{ml}$ ) in acetonitrile to facilitate protein precipitation from the plasma. After centrifugation, the supernatant was evaporated to dryness and reconstituted in assay mobile phase. LC-MS analysis of extract was performed on a $5 \mu \mathrm{m} \mathrm{C} 18$ column $(5 \mathrm{~cm} \times$ $0.21 \mathrm{~cm}$ ) with mass detection by a PE-Sciex API 150EX single quadrupole mass spectrometer under the following conditions:

Mobile Phase: $\quad 0.01 \mathrm{M}$ ammonium acetate $(49.95 \% \mathrm{v} / \mathrm{v})$ : acetonitrile $(49.95 \% \mathrm{v} / \mathrm{v})$ : glacial acetic acid $(0.10 \% \mathrm{v} / \mathrm{v})$

Flow Rate: $\quad 0.3 \mathrm{ml} / \mathrm{min}$

Split Ratio: $\quad 1: 5$

Data acquisition and integration were achieved using a Macintosh computer system running PE Sciex Masschrom version 1.1.1 data handling software incorporating MACQUAN version 1.6 software.

\section{Study endpoints}

The primary endpoints were the pharmacokinetic variables $\mathrm{T}_{\text {max }} \mathrm{C}_{\text {max }^{\prime}} \mathrm{AUC}_{0-\mathrm{t}}$ and $\mathrm{AUC}_{0 \text {-inf }}($ Table 1) derived from the plasma ibuprofen concentrations for the three formulations. As a secondary pharmacokinetic endpoint, the cumulative AUCs at each blood sampling time point up to 1 hour after dosing were compared in order to fully

Table I: Pharmacokinetic variables and their definitions

\begin{tabular}{|c|c|}
\hline $\mathbf{T}_{\max }$ & The time to the first occurrence of the maximum plasma concentration \\
\hline$C_{\max }$ & The observed maximum plasma concentration \\
\hline AUC $_{0-\mathrm{t}}$ & $A \cup C$ to the last measurable plasma concentration $\left(C_{p}\right)$, calculated by the linear trapezoidal rule \\
\hline AUC $_{0 \text {-inf }}$ & $\begin{array}{l}\text { AUC calculated by linear trapezoidal rule to the last measurable } C_{p} \text { with additional area calculated from } C_{p} / K e l . ~ K e l \text { is the } \\
\text { elimination rate constant calculated from the slope of the terminal portion of the plasma profile calculated by least-squares } \\
\text { regression of log (concentration) against time }\end{array}$ \\
\hline
\end{tabular}


Table 2: $C_{\max }, A \cup C_{0-t}, A \cup C_{0-\text { inf }}$ and $T_{\text {max }}$ data

\begin{tabular}{|c|c|c|c|}
\hline & $\begin{array}{l}\text { Sodium ibuprofen } \\
(n=22)\end{array}$ & $\begin{array}{l}\text { Ibuprofen/poloxamer } \\
(n=22)\end{array}$ & $\begin{array}{l}\text { Standard ibuprofen } \\
(n=22)\end{array}$ \\
\hline \multicolumn{4}{|l|}{$C_{\max }(\mu g / m L)$} \\
\hline Arithmetic mean & 43.01 & 36.06 & 32.84 \\
\hline Geometric LS mean & 41.47 & 35.22 & 31.88 \\
\hline \multicolumn{4}{|l|}{$\operatorname{AUC}_{0-\mathrm{t}}(\mu \mathrm{g} / \mathrm{mL} / \mathrm{h})$} \\
\hline Arithmetic mean & 120.57 & 124.10 & 119.10 \\
\hline Geometric LS mean & 117.79 & 120.55 & 115.28 \\
\hline \multicolumn{4}{|l|}{$\mathrm{AUC}_{0 \text {-inf }}(\mu \mathrm{g} / \mathbf{m L} / \mathbf{h})$} \\
\hline Arithmetic mean & 122.88 & 126.72 & 121.99 \\
\hline Geometric LS mean & 119.73 & 122.75 & II7.71 \\
\hline \multicolumn{4}{|l|}{$T_{\max }(\min )$} \\
\hline Median & 35 & 75 & 90 \\
\hline
\end{tabular}

LS: least-squares

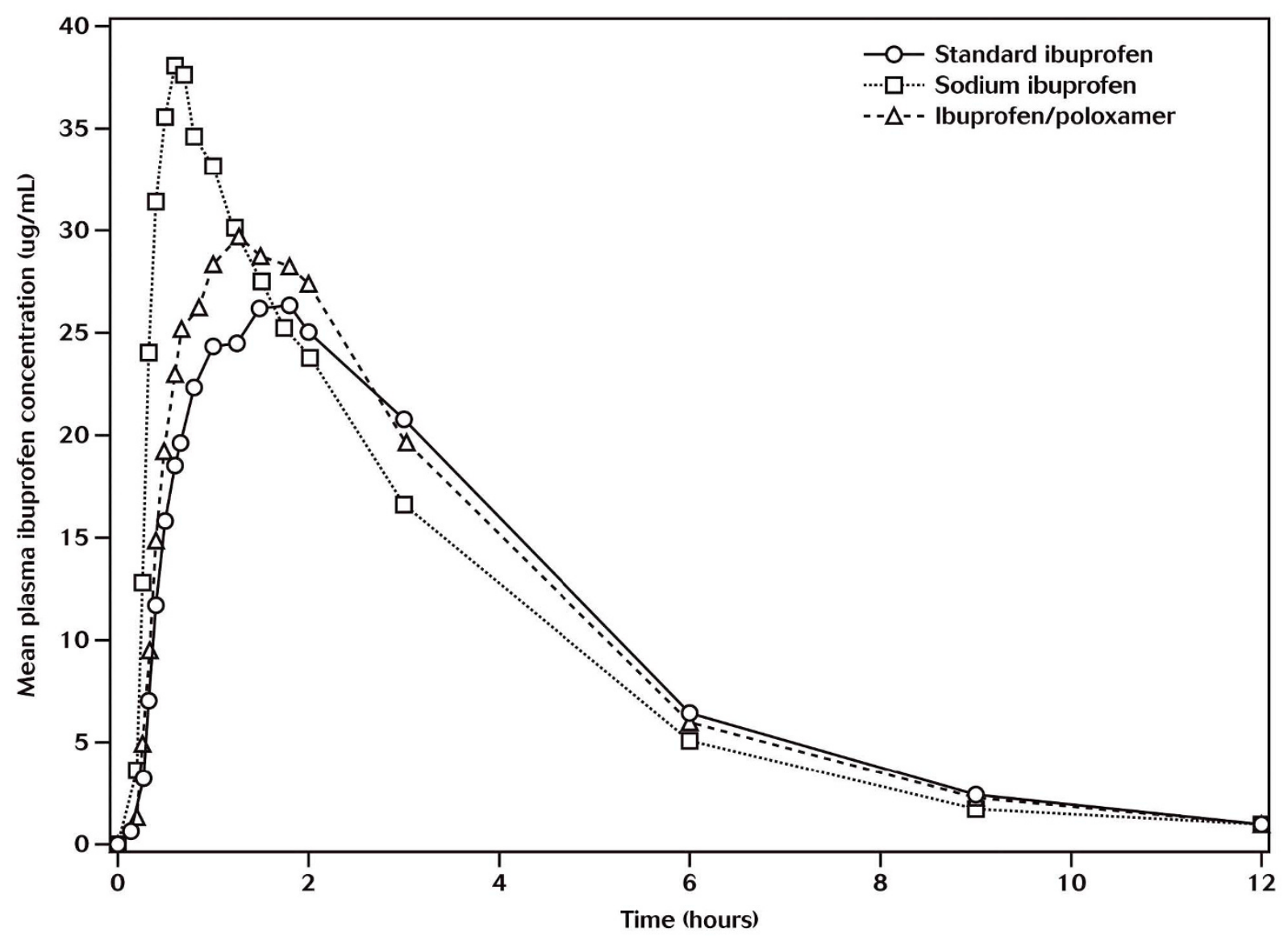

Figure I

Mean plasma ibuprofen concentrations ( $\mu \mathrm{g} / \mathrm{mL})$. 


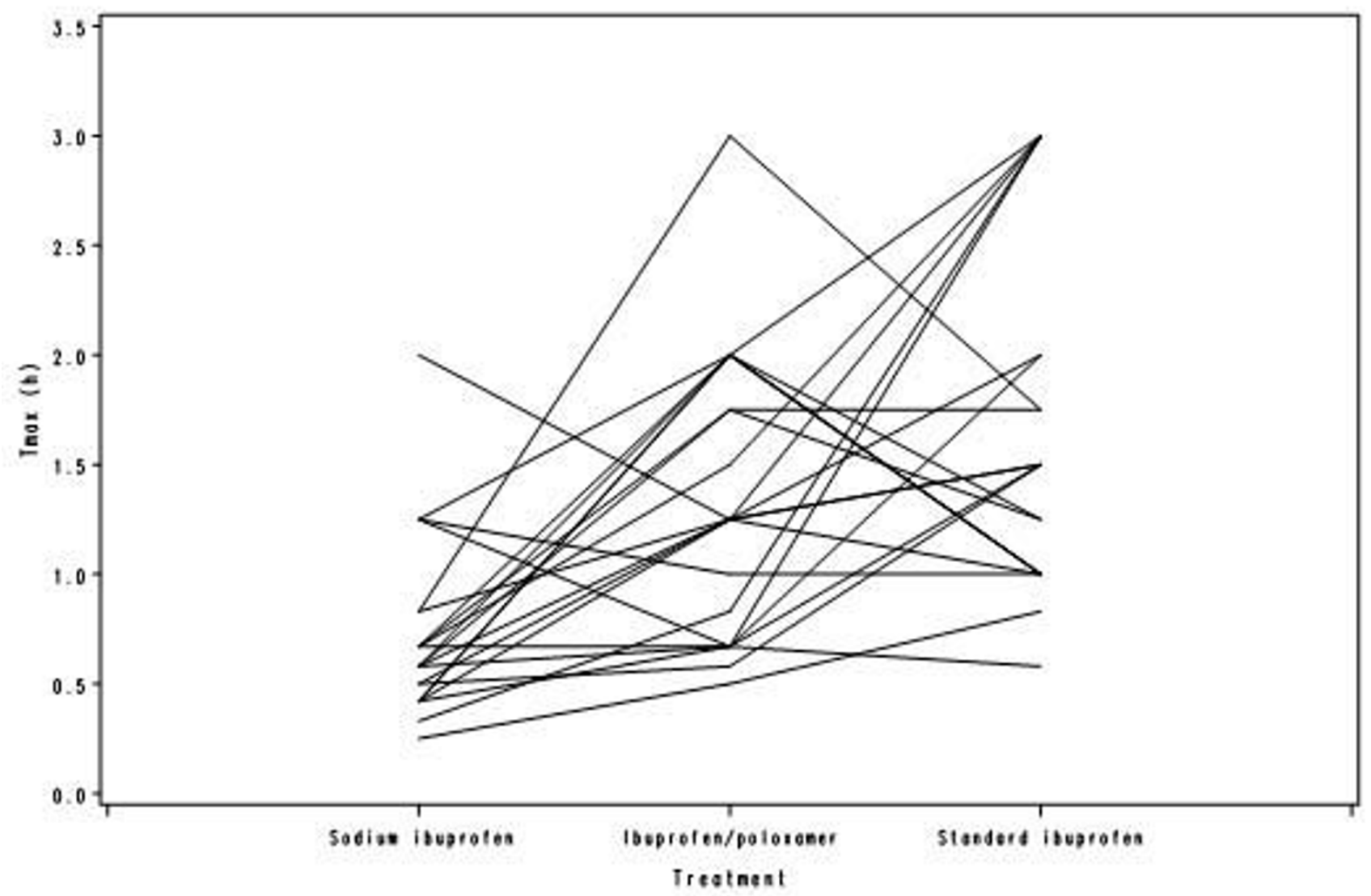

Figure 2

Spaghetti plot of $\mathbf{T}_{\max }$.

explore any differences in the rate of drug absorption between the three formulations.

\section{Sample size determination}

The sample size of this study was based on previous work with other similarly fast-absorbed ibuprofen formulations in which the within-subject coefficient of variation for ibuprofen $\mathrm{C}_{\max }$ was found to be $20 \%$. Therefore, using the method of Diletti et al. [18], a sample size of 20 subjects was considered sufficient to detect a $20 \%$ difference between the test and reference formulations with a power of $80 \%$ and alpha of $5 \%$, based upon a test versus reference ratio of 1.05. Since the main parameter of interest in this study was $T_{\text {max }}$ the sample size calculation was also based on $\mathrm{T}_{\max }$. The within-subject standard deviation for $\mathrm{T}_{\max }$ in the previous studies was found to be approximately 70 minutes. In order to detect a difference of 40 minutes in $\mathrm{T}_{\max }$ between the test and reference formulations, it was calculated that a sample size of 20 subjects would be required to give a power of $85 \%$. Furthermore, the sample size of this study was in line with that used in similar published studies [19].

\section{Statistical analyses}

$\mathrm{T}_{\max }$ was analysed using a Wilcoxon matched pairs test. A $95 \%$ non-parametric confidence interval (CI) was constructed for the median difference in the $\mathrm{T}_{\max }$ values based on the Hodges-Lehmann estimates.

For the cumulative AUC, $\mathrm{AUC}_{0-\mathrm{t}}, \mathrm{AUC}_{0 \text {-inf }}$ and $\mathrm{C}_{\text {max }}$ data, analysis of variance, including the terms for sequence, subject nested within sequence, period and formulation, was carried out on logarithmically transformed data. Point estimates and 90\% CIs for the difference between each test treatment and the reference treatment were constructed and then back transformed to give estimates of the ratio of the geometric least squares means and $90 \%$ CIs for the ratios.

\section{Results \\ Demographics}

A total of 22 participants (15 males and 7 females) qualified for enrolment and were randomised to treatment. The mean age of all participants was 27.2 years and the 


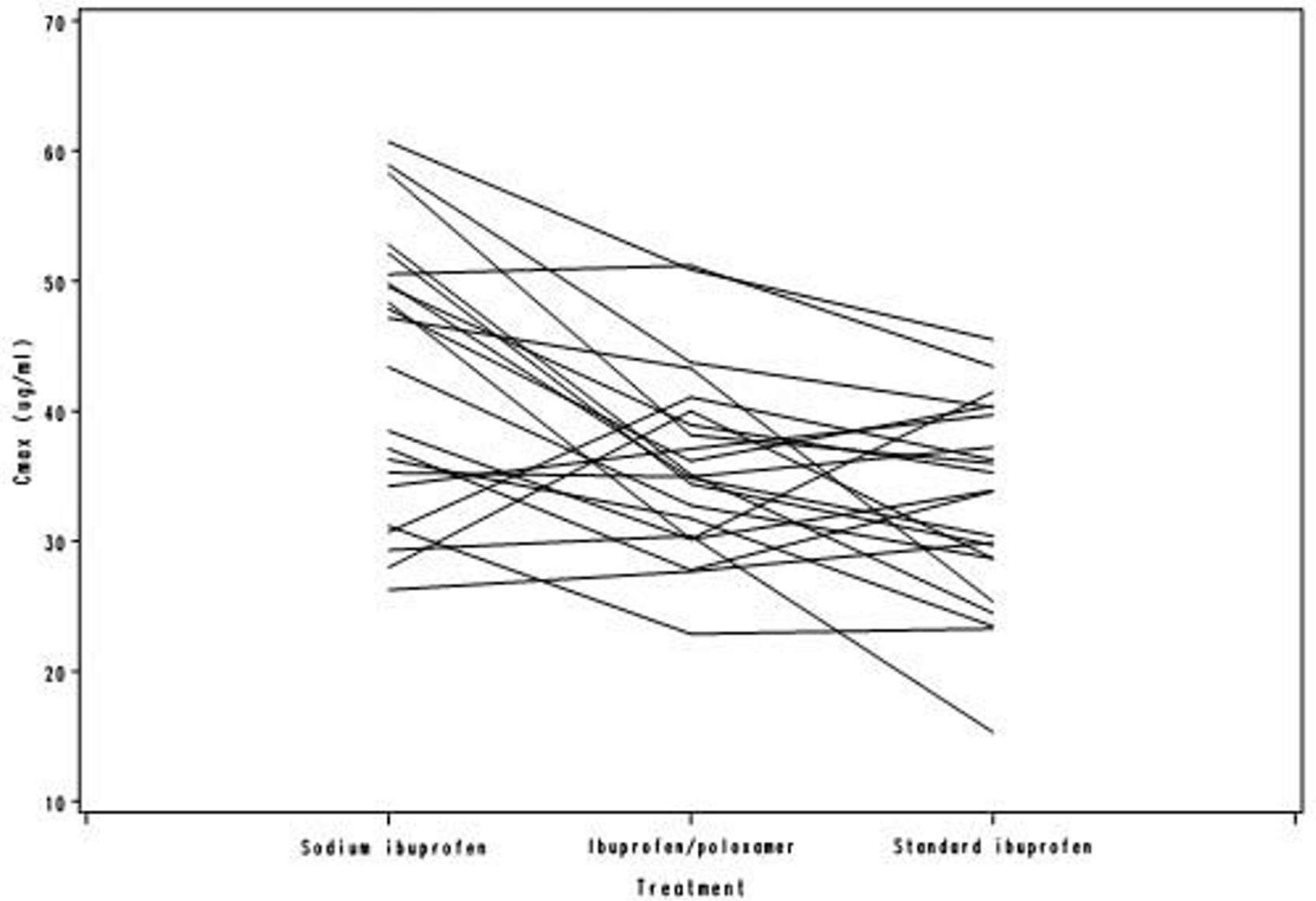

Figure 3

Spaghetti plot of $C_{\max }$.

mean BMI was $24.1 \mathrm{~kg} / \mathrm{m}^{2}$. No participants withdrew from the study.

\section{Pharmacokinetic endpoints}

Figure 1 shows the mean plasma concentrations of the two test and one reference ibuprofen formulations. The mean values for $\mathrm{C}_{\text {max }}, \mathrm{AUC}_{0 \text {-t }}$ and $\mathrm{AUC}_{0 \text {-inf }}$ and the median values for $\mathrm{T}_{\max }$ are presented in Table 2 . Administration of sodium ibuprofen resulted in a significantly shorter time to peak plasma concentration $\left(\mathrm{T}_{\max }\right)$, compared with standard ibuprofen (median $35 \mathrm{~min}$ vs $90 \mathrm{~min} ; P<$ 0.0002). $\mathrm{T}_{\max }$ for sodium ibuprofen was on average 55 minutes shorter than with standard ibuprofen.

Although the $\mathrm{T}_{\max }$ for ibuprofen/poloxamer was on average 20 minutes shorter than that of the standard ibuprofen formulation, this difference was not statistically significant (median $75 \mathrm{~min}$ vs $90 \mathrm{~min} ; P=0.1913$ ). The power in terms of $\mathrm{T}_{\max }$ for a $P$-value of 0.0002 was $>99 \%$ and for a $P$-value of 0.1913 was $31 \%$.
The $\mathrm{C}_{\max }$ results obtained for the sodium ibuprofen formulation and the standard ibuprofen formulation were 41.47 and $31.88 \mu \mathrm{g} / \mathrm{mL}$, respectively (geometric LS means). The ratio of the test/reference was $130.06 \%$ with $90 \%$ CIs of $118.86-142.32 \%$. The $\mathrm{C}_{\max }$ obtained for the ibuprofen/poloxamer tablets was $35.22 \mu \mathrm{g} / \mathrm{mL}$. The ratio of the test/reference was $110.48 \%$ with $90 \%$ CIs of 100.96-120.89\%.

For overall extent of absorption, all three formulations were equivalent, with test/standard formulation ratios of both $\mathrm{AUC}_{0 \text {-inf }}$ and $\mathrm{AUC}_{0-\mathrm{t}}$ very close to $100 \%$. The $\mathrm{AUC}_{0-\mathrm{t}}$ values were $117.79 \mu \mathrm{g} / \mathrm{h} / \mathrm{mL}, 120.55 \mu \mathrm{g} / \mathrm{h} / \mathrm{mL}$ and 115.28 $\mu \mathrm{g} / \mathrm{h} / \mathrm{mL}$ for sodium ibuprofen, ibuprofen/poloxamer and standard ibuprofen, respectively. The $\mathrm{AUC}_{0 \text {-inf }}$ values were $119.73 \mu \mathrm{g} / \mathrm{h} / \mathrm{mL}, 122.75 \mu \mathrm{g} / \mathrm{h} / \mathrm{mL}$ and $117.71 \mu \mathrm{g} / \mathrm{h} /$ $\mathrm{mL}$ for sodium ibuprofen, ibuprofen/poloxamer and standard ibuprofen, respectively. 


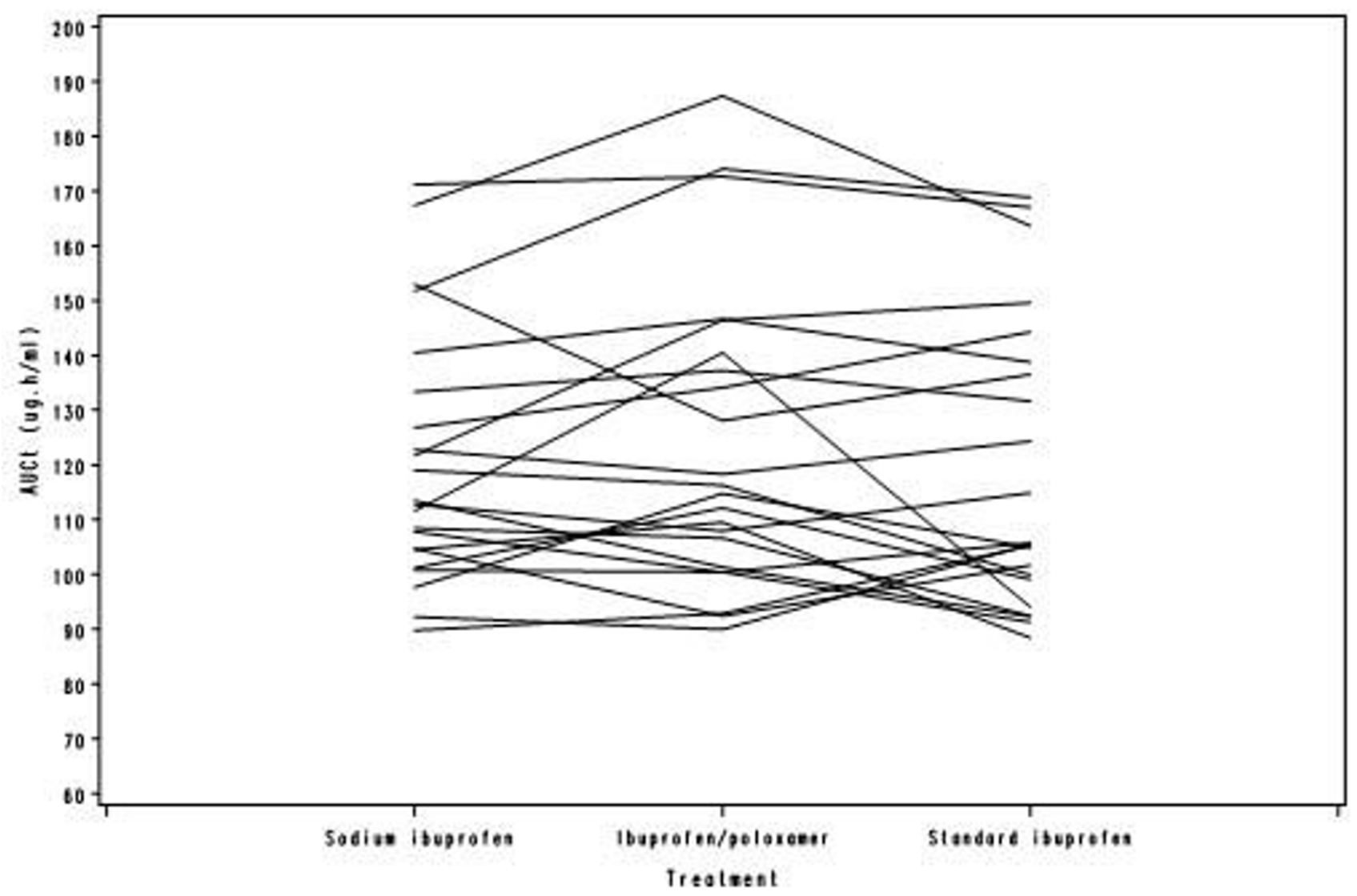

Figure 4

Spaghetti plot of $\mathrm{AUC}_{0-\mathrm{t}}$.

Table 3 shows the ratios of the sodium ibuprofen/standard formulations and the ibuprofen/poloxamer/standard formulations for partial AUC. Throughout the first hour post dose, the partial AUCs for both the sodium ibuprofen and ibuprofen/poloxamer formulations were higher than those for the standard ibuprofen formulation, with the greatest test/standard formulation absorption ratio occurring at 20 minutes for both test formulations (Table 3 ). The spaghetti plots provide individual subject information per treatment, for each of the four derived pharmacokinetic parameters (Figures 2, 3, 4 and 5). In general, $\mathrm{C}_{\max }$ was found to be higher and $\mathrm{T}_{\max }$ was lower for sodium ibuprofen than ibuprofen/poloxamer or standard ibuprofen (Figures 2, 3, 4 and 5).

There were no serious adverse events and no withdrawals from the study because of an adverse event. Three individuals reported a total of four adverse events, three of which were considered mild and one moderate, but none was considered to be related to the study drugs.

\section{Discussion}

This study showed that the $\mathrm{T}_{\max }$ for the sodium ibuprofen formulation was less than half that of the standard ibuprofen acid formulation, suggesting that the rate of absorption of sodium ibuprofen was twice as fast as that of standard ibuprofen tablets. As expected, this increased rate of absorption was accompanied by an increase in the peak plasma concentration of ibuprofen. Furthermore, the CI of the ratio of the sodium ibuprofen/standard ibuprofen tablets for $\mathrm{C}_{\max }$ was outside the $80-125 \%$ limit specified in the Committee for Proprietary Medicinal Products (CPMP) guidelines [20] and the United States Food and Drug Administration (US FDA) guidelines for bioavailability and bioequivalence [21]. The fact that the sodium ibuprofen formulation was not bioequivalent with the standard ibuprofen acid formulation was expected given the faster absorption of ibuprofen from the sodium formulation. This is likely to be due to faster dissolution and more rapid availability of ibuprofen particles for absorption, as suggested by Sorgel et al. [9]. 


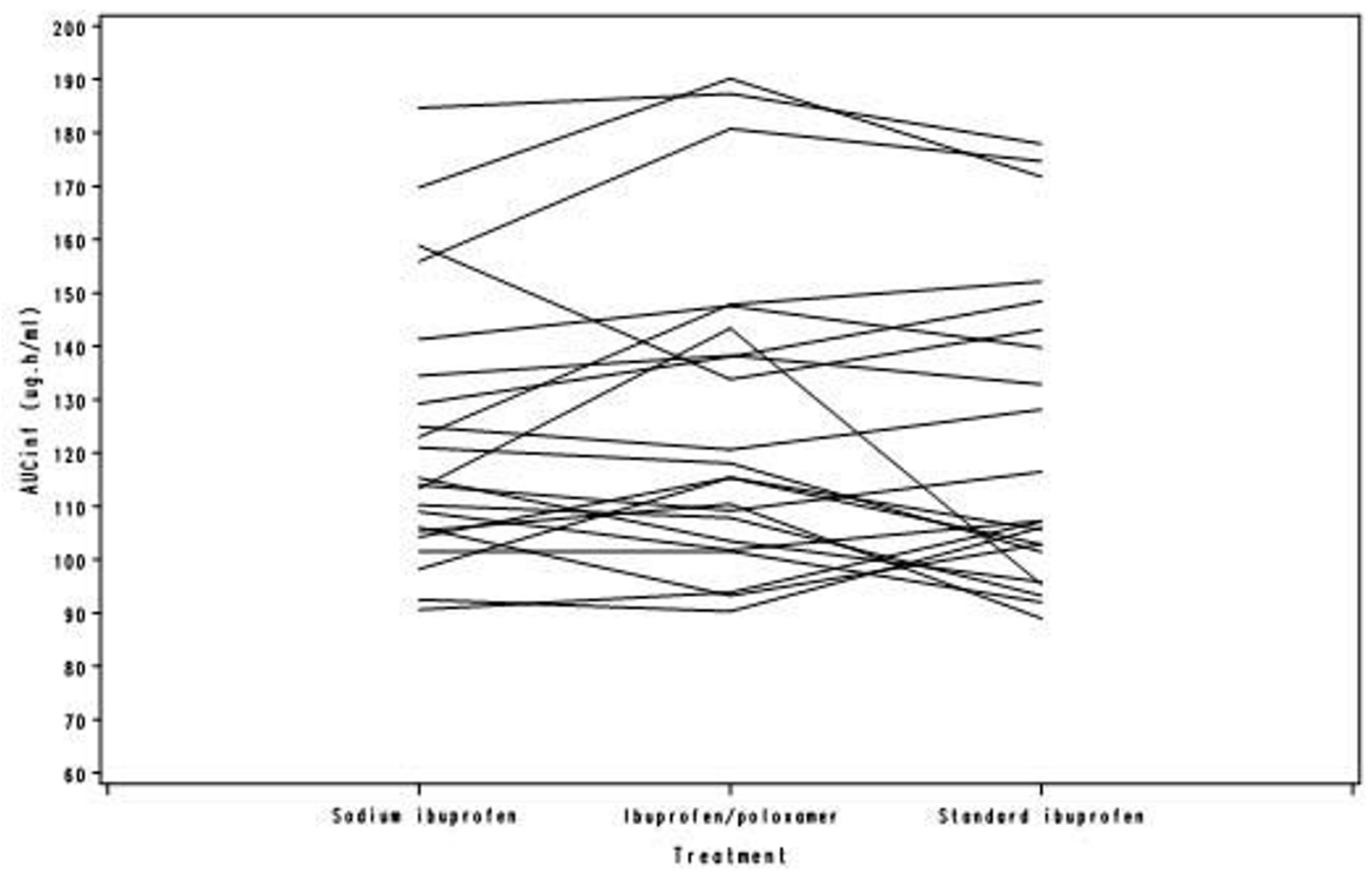

Figure 5

Spaghetti plot of $A U C_{0 \text {-inf }}$

The literature suggests that the addition of poloxamer 407 to the ibuprofen acid formulation might have resulted in a faster absorption of ibuprofen than from standard ibuprofen formulation [15]. Although the time to reach the peak plasma concentration was, on average, 20 minutes faster with the ibuprofen/poloxamer tablets, this difference failed to achieve statistical significance. As it had been anticipated that the difference in $\mathrm{T}_{\max }$ between the ibuprofen acid and ibuprofen/poloxamer formulations would be 40 minutes, the study was not sufficiently powered (i.e. $31 \%$ only) for the observed difference to be statistically significant. The CI of the ratio of the ibuprofen/ poloxamer to the standard ibuprofen tablets for $\mathrm{C}_{\max }$ was within the $80-125 \%$ limit specified in the CPMP guidelines [20] and FDA guidelines [21]. As the CI of the ratio of the ibuprofen/poloxamer to the standard ibuprofen tablets for AUC also fell within this limit, the ibuprofen/ poloxamer and standard ibuprofen formulations can be considered bioequivalent.

The differences between the sodium ibuprofen formulation and the standard ibuprofen formulation would not be expected to result in adverse clinical consequences in terms of either safety or efficacy. In support of this, there were no clinically significant safety findings in the present study.

The data from this study show that the overall amount of drug to which the participants were exposed was the same for the three formulations. However, because of the faster absorption of ibuprofen from the sodium ibuprofen formulation compared with the standard formulation, it is expected that an OTC dose of two $256 \mathrm{mg}$ sodium ibuprofen tablets may provide faster onset of analgesia without compromising safety or duration of analgesia. Previous studies have demonstrated that the median time to meaningful pain relief for ibuprofen arginate was half that of the standard ibuprofen $[6,13,14]$. Because the $\mathrm{T}_{\max }$ for sodium ibuprofen in this study (median: $35 \mathrm{~min}$ ) was found to be similar to ibuprofen arginate (mean: 33.6 min) [9], it can be expected that sodium ibuprofen would induce analgesic effects with a similar onset of action as ibuprofen arginate. Such a formulation would be a valuable addition to the OTC choice currently available to individuals with acute pain. To this extent, a clinical trial was 
Table 3: Statistical analyses of partial AUC data

\begin{tabular}{|c|c|c|c|c|c|c|c|}
\hline & $\begin{array}{l}\text { Sodium } \\
\text { ibuprofen } \\
\text { (geometric } \\
\text { means) }\end{array}$ & $\begin{array}{l}\text { Ibuprofen/ } \\
\text { poloxamer } \\
\text { (geometric } \\
\text { means) }\end{array}$ & $\begin{array}{l}\text { Standard } \\
\text { ibuprofen } \\
\text { (geometric } \\
\text { means) }\end{array}$ & $\begin{array}{l}\text { Ratio (\%) } \\
\text { sodium } \\
\text { ibuprofen/ } \\
\text { standard } \\
\text { ibuprofen }\end{array}$ & $\begin{array}{l}90 \% \\
\text { confidence } \\
\text { interval }\end{array}$ & $\begin{array}{l}\text { Ratio (\%) } \\
\text { ibuprofen/ } \\
\text { poloxamer/ } \\
\text { standard } \\
\text { ibuprofen }\end{array}$ & $\begin{array}{l}90 \% \\
\text { confidence } \\
\text { interval }\end{array}$ \\
\hline $\begin{array}{l}\text { AUC 0-0.08 } \\
(\mu \mathrm{g} / \mathrm{h} / \mathrm{mL})\end{array}$ & Not estimated & Not estimated & Not estimated & Not estimated & Not estimated & Not estimated & Not estimated \\
\hline $\begin{array}{l}\text { AUC 0-0.17 } \\
(\mu \mathrm{g} / \mathrm{h} / \mathrm{mL})\end{array}$ & 0.06 & 0.03 & 0.03 & 217.32 & $95.29-495.60$ & 118.65 & $49.21-286.08$ \\
\hline $\begin{array}{l}\text { AUC 0-0.25 } \\
(\mu \mathrm{g} / \mathrm{h} / \mathrm{mL})\end{array}$ & 0.49 & 0.13 & 0.09 & 529.77 & $262.01-1071.16$ & 138.56 & $68.53-280.17$ \\
\hline $\begin{array}{l}\text { AUC 0-0.33 } \\
(\mu \mathrm{g} / \mathrm{h} / \mathrm{mL})\end{array}$ & $1.6 \mid$ & 0.50 & 0.18 & 905.93 & $462.33-1775.19$ & 278.80 & |42.28-546.3| \\
\hline $\begin{array}{l}\text { AUC 0-0.42 } \\
(\mu \mathrm{g} / \mathrm{h} / \mathrm{mL})\end{array}$ & 3.57 & 1.24 & 0.55 & 644.02 & $362.66-1143.69$ & 224.33 & | 26.32-398.37 \\
\hline $\begin{array}{l}\text { AUC 0-0.50 } \\
(\mu \mathrm{g} / \mathrm{h} / \mathrm{mL})\end{array}$ & 6.09 & 2.34 & 1.31 & 466.40 & $287.78-755.90$ & |79.0| & I 10.45-290.13 \\
\hline $\begin{array}{l}\text { AUC 0-0.58 } \\
(\mu \mathrm{g} / \mathrm{h} / \mathrm{mL})\end{array}$ & 8.99 & 3.72 & 2.30 & 390.44 & $251.21-606.85$ & 161.71 & $|04.04-25| .34$ \\
\hline $\begin{array}{l}\text { AUC 0-0.67 } \\
(\mu \mathrm{g} / \mathrm{h} / \mathrm{mL})\end{array}$ & 12.08 & 5.39 & 3.52 & 343.55 & $227.18-519.53$ & 153.34 & $101.40-231.89$ \\
\hline $\begin{array}{l}\text { AUC 0-0.83 } \\
(\mu \mathrm{g} / \mathrm{h} / \mathrm{mL})\end{array}$ & 18.03 & 9.24 & 6.36 & 283.49 & | $95.09-4 \mid 1.95$ & $|45.2|$ & $99.93-211.00$ \\
\hline $\begin{array}{l}\text { AUC 0-I.00 } \\
(\mu g / h / m L)\end{array}$ & 23.71 & 13.65 & 9.54 & 248.48 & I 76.57-349.68 & 143.08 & $101.67-201.35$ \\
\hline
\end{tabular}

conducted to explore this and data are published separately [22].

\section{Conclusion}

The sodium ibuprofen formulation is equivalent to standard ibuprofen in terms of extent of absorption, but its rate of absorption, as measured by $\mathrm{T}_{\text {max }}$ is significantly faster (i.e. it was absorbed twice as fast as standard ibuprofen) and $\mathrm{C}_{\max }$ is significantly higher. However, the ibuprofen/ poloxamer formulation was bioequivalent to the standard ibuprofen formulation. Therefore, it is expected that an OTC dose of two $256 \mathrm{mg}$ sodium ibuprofen tablets may provide faster onset of analgesic benefit, without compromising safety.

\section{Competing interests}

This study was funded by Reckitt Benckiser Group plc. The Principal Investigator, Peter Dewland, was Medical Director at Simbec Research, UK. Sandie Reader and Phillip Berry are employees of Reckitt Benckiser Group plc.

\section{Authors' contributions}

PD was the Principal Investigator and was responsible for the conduct of the study at Simbec. SR was the Clinical Project Manager at Reckitt Benckiser Healthcare (UK) and was the primary contact between Simbec and the sponsor. PB is the Global Medical Director at Reckitt Benckiser Healthcare UK. All authors read and approved the final manuscript.

\section{Acknowledgements}

The authors would like to acknowledge Darren Hughes (Simbec Research Ltd) for statistical support and Vandana Sahajpal, PhD and Quyen Chu, PhD (Sudler \& Hennessey, London) for medical writing/editorial support.

\section{References}

I. Davies NM: Clinical pharmacokinetics of ibuprofen. The first 30 years. Clin Pharmacokinet 1998, 34:10I-I54.

2. Neupert W, Brugger R, Euchenhofer C, Brune K, Geisslinger G: Effects of ibuprofen enantiomers and its coenzyme $A$ thioesters on human prostaglandin endoperoxide synthases. Br J Pharmacol 1997, I 22:487-492.

3. Martinez MN, Amidon GL: A mechanistic approach to understanding the factors affecting drug absorption: a review of fundamentals. J Clin Pharmacol 2002, 42:620-643.

4. Albert KS, Gernaat CM: Pharmacokinetics of ibuprofen. Am J Med 1984, 77:40-46.

5. Laska EM, Sunshine A, Marrero I, Olson N, Siegel C, McCormick N: The correlation between blood levels of ibuprofen and clinical analgesic response. Clin Pharmacol Ther 1986, 40:I-7.

6. Mehlisch DR, Ardia A, Pallotta T: A controlled comparative study of ibuprofen arginate versus conventional ibuprofen in the treatment of postoperative dental pain. J Clin Pharmacol 2002, 42:904-9II.

7. Geisslinger G, Dietzel K, Bezler H, Nuernberg B, Brune K: Therapeutically relevant differences in the pharmacokinetical and pharmaceutical behavior of ibuprofen lysinate as compared to ibuprofen acid. Int J Clin Pharmacol Ther Toxicol 1989, 27:324-328.

8. Johnson ES, Ratcliffe DM, Wilkinson M: Naproxen sodium in the treatment of migraine. Cephalalgia 1985, 5:5-10.

9. Sorgel F, Fuhr U, Minic M, Siegmund M, Maares J, Jetter A, KinzigSchippers M, Tomalik-Scharte D, Szymanski J, Goeser T, Toex U, Scheidel B, Lehmacher W: Pharmacokinetics of ibuprofen sodium dihydrate and gastrointestinal tolerability of shortterm treatment with a novel, rapidly absorbed formulation. Int J Clin Pharmacol Ther 2005, 43: I 40-149.

10. Martin W, Koselowske G, Toberich H, Kerkmann T, Mangold B, Augustin J: Pharmacokinetics and absolute bioavailability of 
ibuprofen after oral administration of ibuprofen lysine in man. Biopharm Drug Dispos 1990, I I:265-278.

II. Klueglich M, Ring A, Scheuerer S, Trommeshauser D, Schuijt C, Liepold B, Berndl G: Ibuprofen extrudate, a novel, rapidly dissolving ibuprofen formulation: relative bioavailability compared to ibuprofen lysinate and regular ibuprofen, and food effect on all formulations. J Clin Pharmacol 2005, 45: 1055-106I.

12. Schleier P, Prochnau A, Schmidt-Westhausen AM, Peters H, Becker J, Latz T, Jackowski J, Peters EU, Romanos GE, Zahn B, Lüdemann J, Maares J, Petersen B: Ibuprofen sodium dihydrate, an ibuprofen formulation with improved absorption characteristics, provides faster and greater pain relief than ibuprofen acid. Int J Clin Pharmacol Ther 2007, 45:89-97.

13. Black P, Max MB, Desjardins P, Norwood T, Ardia A, Pallotta T: A randomized, double-blind, placebo-controlled comparison of the analgesic efficacy, onset of action, and tolerability of ibuprofen arginate and ibuprofen in postoperative dental pain. Clin Ther 2002, 24:1072-1089.

14. Desjardins P, Black P, Papageorge M, Norwood T, Shen DD, Norris $L$, Ardia $A$ : Ibuprofen arginate provides effective relief from postoperative dental pain with a more rapid onset of action than ibuprofen. Eur J Clin Pharmacol 2002, 58:387-394.

15. Newa M, Bhandari KH, Oh DH, Kim YR, Sung JH, Kim JO, Woo JS, Choi HG, Yong CS: Enhanced dissolution of ibuprofen using solid dispersion with poloxamer 407. Arch Pharm Res 2008, 3I:I497-I507.

16. World Medical Association Declaration of Helsinki: Ethical Principles for Medical Research Involving Human Patients. Adopted by the 18th WMA General Assembly 1964 and amended by the 29th, 35th, 4Ist and 48th WMA General Assemblies .

17. Directive 200I/20/EC of the European Parliament and of the Council on the approximation of the laws, regulations and administrative provisions of the Member States relating to the implementation of good clinical practice in the conduct of clinical trials on medicinal products for human use [http:/ /www.wctn.org.uk/downloads/EU Directive/Directive.pdf]

18. Diletti E, Hauschke D, Steinijans VW: Sample size determination for bioequivalence assessment by means of confidence intervals. Int J Clin Pharmacol Ther Toxicol I991, 29: I-8.

19. Schettler T, Paris S, Pellett M, Kidner S, Wilkinson D: Comparative pharmacokinetics of two fast-dissolving oral ibuprofen formulations and a regular-release ibuprofen tablet in healthy volunteers. Clin Drug Investig 200I, 21:73-78.

20. Note for Guidance on the Investigation of Bioavailability and Bioequivalence CPMP/EWP/QWP//40//98 2002 [http:// www.emea.europa.eu/pdfs/human/qwp//40198enrevl.pdf].

21. Guidance for Industry. Statistical approaches to establishing bioequivalence FDA 200I [http://www.fda.gov/downloads/Drugs/ .../Guidances/ucm070244.pdf].

22. Daniels S, Reader S, Berry P, Goulder M: Onset of analgesia with sodium ibuprofen, ibuprofen acid and incorporating poloxamer and acetaminophen - a single-dose, double-blind, placebo-controlled study in patients with post-operative dental pain. Eur J Clin Pharmacol 2009, 65:343-353.

\section{Pre-publication history}

The pre-publication history for this paper can be accessed here:

http://www.biomedcentral.com/1472-6904/9/19/prepub
Publish with Biomed Central and every scientist can read your work free of charge

"BioMed Central will be the most significant development for disseminating the results of biomedical research in our lifetime. "

Sir Paul Nurse, Cancer Research UK

Your research papers will be:

- available free of charge to the entire biomedical community

- peer reviewed and published immediately upon acceptance

- cited in PubMed and archived on PubMed Central

- yours - you keep the copyright
BioMedcentral 